\title{
Risk Assessment Using Two Different Diagnostic Tools: Metabolic Syndrome and Cardiovascular Risk Score (SCORE) — Data from a Weight Reduction Intervention Study"
}

\author{
Janina Willers, Andreas Hahn \\ Institute of Food Science and Human Nutrition, Leibniz University Hannover, Hannover, Germany. \\ Email: willers@nutrition.uni-hannover.de
}

Received August $2^{\text {nd }}, 2013$; revised September $2^{\text {nd }}, 2013$; accepted September $9^{\text {th }}, 2013$

Copyright (C) 2013 Janina Willers, Andreas Hahn. This is an open access article distributed under the Creative Commons Attribution License, which permits unrestricted use, distribution, and reproduction in any medium, provided the original work is properly cited.

\begin{abstract}
Objective: Risk score models and the diagnosis of a metabolic syndrome are useful for cardiovascular (CV) risk prediction. The identification of individuals with high $\mathrm{CV}$ and metabolic risk is essential to provide appropriate prevention and therapy. The present study aims at clarifying whether these indicators are altered by a weight reduction programme. Additionally, which diagnostic tool has a better predictive value is examined. Method: One hundred and twenty overweight and obese subjects aged 30 - 60 years were included in a 12-week weight reduction programme. The CV risk was assessed by means of German multiple-used risk charts (SCORE) at baseline and at the end of the trial. Furthermore, the prevalence of the metabolic syndrome (three out of five risk factors) was quantified. Results: The initial prevalence of the metabolic syndrome was $63.3 \%(n=76)$ and decreased to $41.7 \%(n=50)$ by the end of the intervention. The SCORE also decreased significantly after twelve weeks $(\mathrm{p}<0.001)$. The percentage of subjects at high risk $(\mathrm{SCORE}>5 \%)$ was comparatively low $\left(\mathrm{t}_{0}: 7.4 \%, \mathrm{n}=7 ; \mathrm{t}_{12}: 5.3 \%, \mathrm{n}=5\right)$. Conclusion: The weight reduction concept was applicable to improve the CV risk SCORE and decrease the prevalence of the metabolic syndrome. The CV 10-year risk calculated using German risk charts (SCORE) probably underestimated the risk of CV diseases in this collective. In this case, the diagnosis of a metabolic syndrome is more meaningful than risk SCORE calculations.
\end{abstract}

Keywords: Weight Reduction; Cardiovascular Risk Score; Metabolic Syndrome

\section{Introduction}

Visceral obesity is a major risk factor for many serious conditions, including heart disease, type-2 diabetes, hypertension, stroke, and certain types of cancer [1-3]. Due to their common occurrence, these diseases form a cluster that has been termed metabolic syndrome [4]. Data from prospective population-based cohort studies have shown that obesity appeared to be the central feature of the metabolic syndrome [5-8]. Metabolic syndrome is an established instrument to identify subjects with increased cardiovascular (CV) morbidity and mortality [9]. On the other hand, risk predictions, such as the Framingham risk score [10], PROCAM score [11] and the SCORE of the European Society of Cardiology (ESC) [12,13], are also opportunities for global CV risk assessment. The specific

\footnotetext{
*Funding: the study relevant to the subject of this article was funded by Certmedica International GmbH, Aschaffenburg, Germany.

\#Conflict of interest: the authors declared no conflict of interest.
}

risk tables for the German population, SCORE Deutschland, were designed within the framework of the European Heartscore project and are intended for calculating the 10-year risk of fatal cardiovascular disease (CVD), including stroke, in men and women [13]. It has been shown that this SCORE is a widely used risk assessment tool in Germany and Europe [14]. Identification of highrisk individuals using risk predictions or criteria for the metabolic syndrome is essential to provide appropriate therapy.

The first therapeutic step in lowering $\mathrm{CV}$ and metabolic risk should be weight reduction in combination with increased physical activity. Studies have shown that moderate weight loss and lifestyle intervention can significantly improve several aspects of the metabolic syndrome [15-17].

In this study, we determined the prevalence and characteristics of the metabolic syndrome in overweight and 
obese individuals participating in a weight reduction programme. Furthermore, we examined the effects of weight loss on the components of the metabolic syndrome and a $\mathrm{CV}$ risk score. Additionally, we checked if the two risk calculation methods have a comparable significance.

\section{Material and Methods}

\subsection{Study Population}

One hundred and twenty individuals $(\mathrm{n}=59$ men, $\mathrm{n}=61$ women) participated in a 12-week weight loss programme at the Institute of Food Science and Human Nutrition, Leibniz University Hannover, Germany. The trial protocol has been approved by an ethical committee and meets the standards of the Declaration of Helsinki. The clinical investigation was registered in the German Clinical Trials Register (DRKS) with the identification number DRKS00000325. Written informed consent was obtained from all participants. Further study information, detailed descriptions of the programme and first intervention results have already been published [18]. Detailed information was collected from each patient at baseline and at the end of active weight loss. The examinations included anthropometric and blood pressure measurements, as well as a fasting blood sample. Body Mass Index (BMI) was calculated as weight $(\mathrm{kg})$ divided by height squared $\left(\mathrm{m}^{2}\right)$. Waist circumference (WC) was measured midway between the lowest rib margin and iliac crest with the tape measure all around the body in a horizontal position. Individuals having a WC beyond 88 $\mathrm{cm}$ in women and $102 \mathrm{~cm}$ in men were classified as having a high WC [19]. Blood pressure was measured using a sphygmomanometer after a rest while the patients were seated. Readings were taken three times at intervals of three minutes. The mean value was calculated from this set of readings.

\subsection{Identification of the Metabolic Syndrome}

The criteria according to [20] were used to determine the presence of a metabolic syndrome. The diagnosis of metabolic syndrome was made if at least three out of five risk factors (WC $\geq 102 \mathrm{~cm}$ in men, and $\geq 88 \mathrm{~cm}$ in women; Triglycerides $(\mathrm{TG}) \geq 150 \mathrm{mg} / \mathrm{dl} \geq 1.7 \mathrm{mmol} / \mathrm{l}$; HDL-C $<40 \mathrm{mg} / \mathrm{dl}<1.03 \mathrm{mmol} / \mathrm{l}$ in men, and $<50$ $\mathrm{mg} / \mathrm{dl}<1.29 \mathrm{mmol} / 1$ in women: fasting glucose $\geq 100$ $\mathrm{mg} / \mathrm{dl} \geq 5.6 \mathrm{mmol} / \mathrm{l} ;$ blood pressure $\geq 130 \mathrm{mmHg}$ systolic and/or $\geq 85 \mathrm{mmHg}$ diastolic) were present.

\subsection{SCORE Assessment}

The CV risk score assessment was calculated by using SCORE risk tables for the German population [13]. The SCORE calculation included gender, age, smoking status, systolic blood pressure (SBP), and total cholesterol/
HDL-cholesterol (TC/HDL-C) ratio. Younger people were excluded from this calculation as the risk charts provide age $\geq 40$ years. Due to a consensus [13], a risk of a fatal $\mathrm{CV}$ event in ten years of $>5 \%$ was classified as high risk, so that intensive monitoring and accurate treatment is normally indicated.

\subsection{Statistical Analysis}

Data were analysed using IBM ${ }^{\circledR}$ SPSS $^{\circledR}$ Statistics version 19.0. The results are presented as mean \pm standard deviation (s.d.) for continuous variables and as number of subjects (n) and percentage (\%), respectively, for categorical variables. Differences between men and women, as well as between individuals with and without the metabolic syndrome were calculated using the MannWhitney U test. The changes in the parameters in comparison with baseline were analysed using the Wilcoxon test. Spearman correlation coefficients were used to evaluate association between variables. The McNemar chi-square test was used for the comparison of frequencies. P-values $<0.05$ were considered to be statistically significant. All 120 randomised subjects were assessed on the basis of the Intention-To-Treat (ITT) analysis. The output values were constantly adjusted in subjects without any further values after the baseline measurements (last observation carried forward).

\section{Results}

The basis of the present analysis is a sample of 120 participants from this interventional trial. The baseline characteristics are shown in Table 1.

Table 1. Baseline characteristics of the study population (n =120).

\begin{tabular}{cc}
\hline Parameter & Total study group \\
\hline Sex $[\mathrm{m} / \mathrm{f}]$ & $59 / 61$ \\
Age $[\mathrm{y}]$ & $46.8 \pm 7.2$ \\
BMI $\left[\mathrm{kg} / \mathrm{m}^{2}\right]$ & $32.1 \pm 2.0$ \\
Prevalence Metabolic syndrome [\%] & $63.3(\mathrm{n}=76)$ \\
SCORE [\%] & $1.88 \pm 0.19$ \\
WC [cm] & $106 \pm 8.0$ \\
SBP [mmHg] & $139 \pm 15$ \\
DBP [mmHg] & $94 \pm 11$ \\
TC [mg/dl] & $241 \pm 44.0$ \\
HDL-C [mg/dl] & $54.5 \pm 12.1$ \\
TG [mg/dl] & $174 \pm 117$ \\
Glucose [mg/dl] & $95.9 \pm 12.4$ \\
Smoking [smoker/non-smoker] & $18 / 101$ \\
\hline
\end{tabular}

${ }^{a} \mathrm{n}=95$, age $>40$ years; ${ }^{b}$ one invalid answer. 
The average weight loss from baseline to twelve weeks in the study population was $4.5 \pm 4.0 \mathrm{~kg}$ or $4.6 \% \pm 3.9 \%$ of the initial body weight $(\mathrm{p}<0.001)$. Weight reduction was significantly higher in men than in women $(-5.4 \pm$ $4.6 \mathrm{~kg}$ vs. $-3.4 \pm 3.5 \mathrm{~kg}, \mathrm{p}=0.036)$. The BMI also decreased significantly $\left(-1.4 \pm 1.2 \mathrm{~kg} / \mathrm{m}^{2}, \mathrm{p}<0.001\right)$ in the total study group after twelve weeks (data not shown). Further intervention results have been published elsewhere [18].

\subsection{Prevalence of the Metabolic Syndrome and Changes during Intervention}

The initial prevalence of a metabolic syndrome (at least three out of five risk factors) was $63.3 \%(n=76)$. Men had a statistically significant higher prevalence of the metabolic syndrome at baseline than women ( $n=47$ vs. $n$ $=29, \mathrm{p}<0.001)$. Approximately $21.7 \%(\mathrm{n}=26)$ of individuals had four defining components and 3.3\% $(n=4)$ had all five components of the metabolic syndrome. The most frequent components of the metabolic syndrome at baseline were increased WC and hypertension. Additionally, the highest improvements during the intervention were seen in these components as well. The changes of prevalence were $-17.5 \%$ (WC), $-20 \%$ (blood pressure), $-2.5 \%$ (HDL-C), $-9.1 \%$ (TG), and $-9.2 \%$ (fasting glucose). The prevalence of the single variables of the metabolic syndrome at baseline and after twelve weeks is shown in Figure 1.

After twelve weeks, $41.7 \%(n=50)$ of the subjects still had a metabolic syndrome. Subjects with the metabolic syndrome had statistically significant differences in parameters, such as age, WC, SBP, TC, TG, and glucose, compared with subjects without the metabolic syndrome at any time (Table 2).

The prevalence of individuals with a metabolic syndrome at baseline and even after twelve weeks was

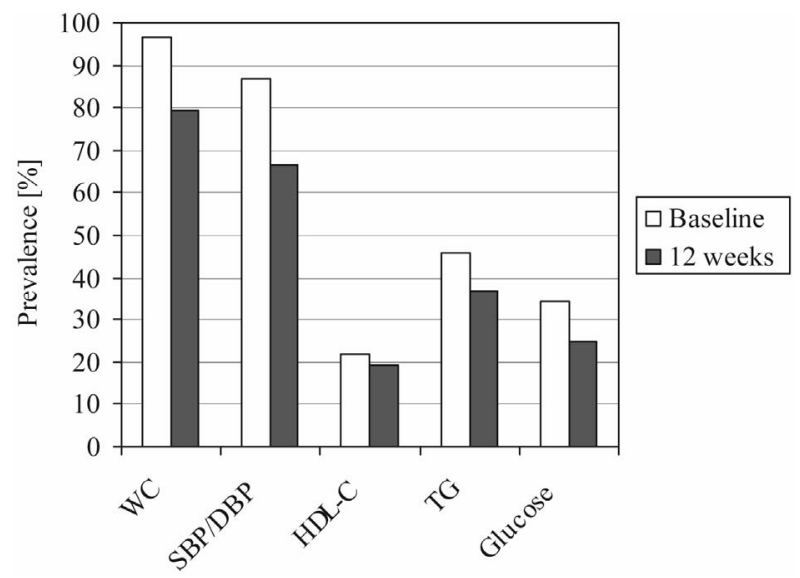

Figure 1. Prevalence of the single components of the metabolic syndrome at baseline and after twelve weeks $(n=120)$.
$38.3 \%(n=46)$. A percentage of $25 \%(n=30)$ had a metabolic syndrome at baseline and were without it at the end of the intervention. Forty of the individuals (33.3\%) had no metabolic syndrome either at baseline or after twelve weeks, and four (3.3\%) developed a metabolic syndrome during the intervention period. The difference between the number of improvements $(n=30)$ and the number of deteriorations $(n=4)$ was, according to the McNemar chi-square test, highly significant $(p<0.001)$.

Differences in comparisons were clearly recognisable by looking at each component of the metabolic syndrome in subjects with various numbers of criteria. Parameters of the metabolic syndrome as a function of the number of criteria fulfilled are shown in Table 3. There was a trend towards increases in each factor in the subjects separated by the number of criteria for the metabolic syndrome, which was statistically significant in stepwise comparison.

The changes in body weight and BMI were significantly associated with the change in each variable of the metabolic syndrome (Table 4). There was also a statistically significant correlation between the changes in weight and BMI with the changes in the $\mathrm{CV}$ risk SCORE.

\subsection{Cardiovascular Risk SCORE}

The SCORE assessment was limited to subjects $\geq 40$ years old. This subgroup of $n=95$ individuals $(n=49$ men, $\mathrm{n}=46$ women) initially had a mean 10 -year CV risk of $1.88 \% \pm 0.19 \%$ (range: $0 \%-11 \%$ ). Smokers and non-smokers were in a ratio of 15:79, respectively (one invalid answer). The mean risk SCORE after the 12week weight loss programme decreased significantly by $-0.27 \% \pm 0.64 \%(\mathrm{p}<0.001)$. This significant improvement was modest and could be seen in both men and women. The CV risk SCORE was statistically significant different between men and women both at the beginning and at the end of the observation period $\left(\mathrm{t}_{0}: 2.4 \% \pm 2.3 \%\right.$ vs. $1.1 \% \pm 1.0 \%, \mathrm{p}<0.001 ; \mathrm{t}_{12}: 2.0 \% \pm 1.9 \%$ vs. $0.9 \% \pm$ $0.9 \%, \mathrm{p}<0.001)$. Components of the CV risk SCORE and the metabolic syndrome in the SCORE subgroup aged $\geq 40$ years at baseline and at the end of the study are presented in Table 5. The differences of the risk SCORE between baseline and after twelve weeks had a low but significant association with the differences of BMI $(\mathrm{r}=$ $0.247, \mathrm{p}=0.016)$ and body weight $(\mathrm{r}=0.274, \mathrm{p}=0.007)$. There was also a significant inverse correlation between the difference of the risk SCORE between baseline and after twelve weeks and the baseline SCORE values $(r=$ $-0.437, \mathrm{p}<0.001)$. The higher the baseline SCORE was, the stronger SCORE decreased during intervention. Further associations were seen, as expected, between the changes in SCORE and the changes in the integrated 

Risk Score (SCORE) — Data from a Weight Reduction Intervention Study

Table 2. Description of individuals with and without the metabolic syndrome at baseline and after twelve weeks $(\mathrm{n}=120)$.

\begin{tabular}{|c|c|c|c|c|c|c|}
\hline \multirow[b]{2}{*}{ Parameter } & \multicolumn{2}{|r|}{ Baseline } & \multicolumn{4}{|c|}{12 weeks } \\
\hline & $\begin{array}{c}\text { With } \\
\text { metabolic syndrome }\end{array}$ & Without metabolic syndrome & $\mathrm{p}^{\mathrm{a}}$ & $\begin{array}{c}\text { With } \\
\text { metabolic syndrome }\end{array}$ & Without metabolic syndrome & $\mathrm{p}^{\mathrm{a}}$ \\
\hline $\mathrm{N}$ & 76 & 44 & & 50 & 70 & \\
\hline $\operatorname{Sex}[\mathrm{m} / \mathrm{f}]$ & $47 / 29$ & $12 / 32$ & $<0.001^{\mathrm{b}}$ & $28 / 22$ & $31 / 39$ & $0.140^{\mathrm{b}}$ \\
\hline Age [years] & $47.9 \pm 7.0$ & $45.0 \pm 7.2$ & 0.030 & $48.9 \pm 7.3$ & $45.4 \pm 6.8$ & 0.005 \\
\hline BMI $\left[\mathrm{kg} / \mathrm{m}^{2}\right]$ & $32.2 \pm 1.9$ & $32.0 \pm 2.1$ & 0.701 & $31.3 \pm 1.9$ & $29.8 \pm 2.4$ & 0.001 \\
\hline $\mathrm{WC}[\mathrm{cm}]$ & $108 \pm 7.3$ & $103 \pm 8.1$ & $<0.001$ & $105 \pm 7.8$ & $98.3 \pm 7.3$ & $<0.001$ \\
\hline $\mathrm{SBP}[\mathrm{mmHg}]$ & $141 \pm 14$ & $134 \pm 15$ & 0.002 & $137 \pm 15$ & $124 \pm 14$ & $<0.001$ \\
\hline DBP [mmHg] & $95 \pm 11$ & $91 \pm 12$ & 0.093 & $92 \pm 11$ & $85 \pm 11$ & $<0.001$ \\
\hline $\mathrm{TC}[\mathrm{mg} / \mathrm{dl}]$ & $247 \pm 44.6$ & $230 \pm 41.1$ & 0.048 & $247 \pm 46.5$ & $224 \pm 41.2$ & 0.010 \\
\hline HDL-C [mg/dl] & $50.2 \pm 10.2$ & $62.0 \pm 11.5$ & $<0.001$ & $52.2 \pm 10.2$ & $56.0 \pm 12.3$ & 0.147 \\
\hline $\mathrm{TG}[\mathrm{mg} / \mathrm{dl}]$ & $209 \pm 130.9$ & $114 \pm 48.2$ & $<0.001$ & $198 \pm 109$ & $120 \pm 64.8$ & $<0.001$ \\
\hline Glucose $[\mathrm{mg} / \mathrm{dl}]$ & $99.1 \pm 13.9$ & $90.3 \pm 6.3$ & $<0.001$ & $102 \pm 14.9$ & $89.4 \pm 7.7$ & $<0.001$ \\
\hline
\end{tabular}

${ }^{\mathrm{a}}$ Mann-Whitney U test, ${ }^{\mathrm{b}}$ chi-square test.

Table 3. Subjects' characteristics according to the number of criteria of the metabolic syndrome fulfilled at baseline and after twelve weeks $(n=120)$.

\begin{tabular}{|c|c|c|c|c|c|c|}
\hline No. of criteria fulfilled & 0 & 1 & 2 & 3 & 4 & 5 \\
\hline \multicolumn{7}{|l|}{ Baseline } \\
\hline BMI $\left[\mathrm{kg} / \mathrm{m}^{2}\right]$ & - & $31.1 \pm 2.0$ & $32.2 \pm 2.0$ & $32.1 \pm 1.9$ & $31.9 \pm 1.9$ & $34.1 \pm 1.0^{*}$ \\
\hline $\mathrm{WC}[\mathrm{cm}]$ & - & $105 \pm 5.1$ & $102 \pm 8.6$ & $107 \pm 7.5^{* *}$ & $109 \pm 6.9$ & $111 \pm 6.6$ \\
\hline $\mathrm{SBP}[\mathrm{mmHg}]$ & - & $125 \pm 6.1$ & $136 \pm 16.2^{*}$ & $140 \pm 12.7$ & $145 \pm 17.1$ & $136 \pm 10.2$ \\
\hline $\mathrm{DBP}[\mathrm{mmHg}]$ & - & $81.9 \pm 6.9$ & $93.3 \pm 11.7^{* *}$ & $94.1 \pm 10.0$ & $96.8 \pm 12.2$ & $91.9 \pm 6.8$ \\
\hline HDL-C [mg/dl] M & - & $52.6 \pm 4.9$ & $60.0 \pm 13.2$ & $49.9 \pm 8.0^{*}$ & $47.1 \pm 11.7^{*}$ & $35.3 \pm 3.1^{*}$ \\
\hline $\mathrm{HDL}-\mathrm{C}[\mathrm{mg} / \mathrm{dl}] \mathrm{F}$ & - & $63.3 \pm 18.8$ & $63.6 \pm 10.7$ & $56.3 \pm 9.7^{*}$ & $49.0 \pm 7.3^{*}$ & 42.0 \\
\hline $\mathrm{TG}[\mathrm{mg} / \mathrm{dl}]$ & - & $101 \pm 22.8$ & $117 \pm 52.0$ & $165 \pm 74.2^{* *}$ & $283 \pm 176^{* * *}$ & $241 \pm 94.5$ \\
\hline Glucose [mg/dl] & - & $90.4 \pm 6.0$ & $90.2 \pm 6.4$ & $95.0 \pm 10.0^{*}$ & $105 \pm 17.8^{*}$ & $110 \pm 1.7$ \\
\hline \multicolumn{7}{|l|}{12 weeks } \\
\hline $\mathrm{N}$ & 4 & 23 & 43 & 37 & 13 & 0 \\
\hline BMI $\left[\mathrm{kg} / \mathrm{m}^{2}\right]$ & $27.9 \pm 1.4$ & $28.9 \pm 2.1$ & $30.5 \pm 2.5^{*}$ & $31.1 \pm 1.9$ & $31.9 \pm 1.9$ & - \\
\hline $\mathrm{WC}[\mathrm{cm}]$ & $94.8 \pm 3.9$ & $95.7 \pm 6.4$ & $100 \pm 7.5$ & $105 \pm 8.2^{* *}$ & $106 \pm 6.4$ & - \\
\hline $\mathrm{SBP}[\mathrm{mmHg}]$ & $115 \pm 7.6$ & $117 \pm 11.7$ & $129 \pm 13.6^{* *}$ & $134 \pm 14.7$ & $142 \pm 13.7$ & - \\
\hline $\mathrm{DBP}[\mathrm{mmHg}]$ & $77.3 \pm 4.5$ & $79.8 \pm 9.3$ & $88.6 \pm 11.4^{* *}$ & $92.4 \pm 11.0$ & $92.3 \pm 10.3$ & - \\
\hline HDL-C $[\mathrm{mg} / \mathrm{dl}] \mathrm{M}$ & $58.0 \pm 5.3$ & $51.8 \pm 12.5$ & $50.1 \pm 13.4$ & $50.4 \pm 11.1$ & $51.0 \pm 11.8$ & - \\
\hline $\mathrm{HDL}-\mathrm{C}[\mathrm{mg} / \mathrm{dl}] \mathrm{F}$ & 83.0 & $60.2 \pm 10.4$ & $56.5 \pm 9.5$ & $55.4 \pm 9.2$ & $49.2 \pm 2.6$ & - \\
\hline $\mathrm{TG}[\mathrm{mg} / \mathrm{dl}]$ & $92.3 \pm 24.6$ & $96.9 \pm 29.1$ & $135 \pm 76.3^{*}$ & $167 \pm 66.9^{* *}$ & $286 \pm 153^{* *}$ & - \\
\hline
\end{tabular}

M: male; F: female; ${ }^{*} \mathrm{p}<0.05 ;{ }^{* *} \mathrm{p}<0.01 ;{ }^{* * *} \mathrm{p}<0.001$. 
Table 4. Correlations (Spearman correlation coefficients) of changes in body weight and BMI with the changes in several variables of the metabolic syndrome in the total study group $(n=120)$.

\begin{tabular}{ccccc}
\hline Variables & $\begin{array}{c}\text { Change in } \\
\text { weight }_{\mathrm{t}_{1}-\mathrm{t}_{0}}\end{array}$ & $\mathrm{p}$ & $\begin{array}{c}\text { Change in } \\
\text { BMI }_{\mathrm{t}_{1}-\mathrm{t}_{0}}\end{array}$ & $\mathrm{p}$ \\
\hline Weight & - & - & 0.981 & $<\mathbf{0 . 0 0 1}$ \\
BMI & 0.981 & $<\mathbf{0 . 0 0 1}$ & - & - \\
WC & 0.756 & $<\mathbf{0 . 0 0 1}$ & 0.761 & $<\mathbf{0 . 0 0 1}$ \\
SBP & 0.403 & $<\mathbf{0 . 0 0 1}$ & 0.410 & $<\mathbf{0 . 0 0 1}$ \\
DBP & 0.389 & $<\mathbf{0 . 0 0 1}$ & 0.385 & $<\mathbf{0 . 0 0 1}$ \\
TC & 0.236 & $\mathbf{0 . 0 0 9}$ & 0.236 & $<\mathbf{0 . 0 1 0}$ \\
HDL-C & -0.134 & 0.144 & -0.100 & 0.278 \\
TC/HDL-C & 0.360 & $<\mathbf{0 . 0 0 1}$ & 0.339 & $<\mathbf{0 . 0 0 1}$ \\
ratio & 0.324 & $<\mathbf{0 . 0 0 1}$ & 0.310 & $\mathbf{0 . 0 0 1}$ \\
TG & 0.264 & $\mathbf{0 . 0 0 4}$ & 0.273 & $\mathbf{0 . 0 0 3}$ \\
Glucose & 0.274 & $\mathbf{0 . 0 0 7}$ & 0.247 & $\mathbf{0 . 0 1 6}$ \\
\hline SCORE & & & &
\end{tabular}

${ }^{a} \mathrm{n}=95$, age $\geq 40$ years.

Table 5. Characteristics of the SCORE subgroup aged $\geq 40$ years at baseline and after twelve weeks $(n=95)$.

\begin{tabular}{cccc}
\hline Parameter & Baseline & 12 weeks & $\mathrm{p}^{\mathrm{a}}$ \\
\hline SCORE [\%] & $1.88 \pm 0.19$ & $1.58 \pm 0.16$ & $<\mathbf{0 . 0 0 1}$ \\
& (range: $0-11)$ & (range: $0-9)$ & \\
Subjects at high risk [\%] & $7.4(\mathrm{n}=7)$ & $5.3(\mathrm{n}=5)$ & $\mathbf{0 . 5 0 0}$ \\
BMI $\left[\mathrm{kg} / \mathrm{m}^{2}\right]$ & $32.2 \pm 1.9$ & $30.5 \pm 2.3$ & $<\mathbf{0 . 0 0 1}$ \\
WC [cm] & $107 \pm 7.8$ & $102 \pm 8.1$ & $<\mathbf{0 . 0 0 1}$ \\
SBP $[\mathrm{mmHg}]$ & $139 \pm 14$ & $130 \pm 15$ & $<\mathbf{0 . 0 0 1}$ \\
DBP $[\mathrm{mmHg}]$ & $94 \pm 11$ & $88 \pm 11$ & $<\mathbf{0 . 0 0 1}$ \\
TC $[\mathrm{mg} / \mathrm{dl}]$ & $246 \pm 44.9$ & $237 \pm 45.7$ & $\mathbf{0 . 0 0 6}$ \\
HDL-C [mg/dl] & $55.3 \pm 11.2$ & $55.4 \pm 10.6$ & 0.942 \\
TC/HDL-C ratio & $4.6 \pm 1.0$ & $4.4 \pm 1.0$ & $\mathbf{0 . 0 0 1}$ \\
TG [mg/dl] & $173 \pm 93.3$ & $154 \pm 88.1$ & $<\mathbf{0 . 0 0 1}$ \\
Glucose $[\mathrm{mg} / \mathrm{dl}]$ & $97.5 \pm 12.5$ & $95.9 \pm 13.5$ & $\mathbf{0 . 0 1 8}$ \\
\hline
\end{tabular}

${ }^{\mathrm{a}}$ Wilcoxon test, ${ }^{\mathrm{b}} \mathrm{McNemar}$ chi-square test.

variables, such as the TC/HDL-C ratio $(\mathrm{r}=0.359, \mathrm{p}<$ $0.001)$ and SBP $(r=0.403, p<0.001)$. We also found significant relations between the changes in SCORE and changes in other traditional $\mathrm{CV}$ risk factors, such as TC $(\mathrm{r}=0.319, \mathrm{p}<0.01)$, LDL-C $(\mathrm{r}=0.260, \mathrm{p}<0.05)$, LDLC/HDL-C ratio $(\mathrm{r}=0.311, \mathrm{p}<0.01), \mathrm{TG}(\mathrm{r}=0.377, \mathrm{p}<$ $0.001)$, and $\mathrm{WC}(\mathrm{r}=0.294, \mathrm{p}<0.01)$. At baseline and after twelve weeks, age had the strongest correlation with the $\mathrm{CV}$ risk SCORE $\left(\mathrm{t}_{0}: \mathrm{r}=0.674, \mathrm{p}<0.001 ; \mathrm{t}_{12}: \mathrm{r}=\right.$ $0.655, \mathrm{p}<0.001)$.

\subsection{Intersection of Risk SCORE and Metabolic Syndrome}

In the SCORE subgroup with an age of 40 and above, $\mathrm{n}=$ $64(67.4 \%)$ of the subjects had a metabolic syndrome at baseline. This proportion decreased after twelve weeks to $\mathrm{n}=44(46.3 \%)$. There was a reduction in the number of subjects $(\mathrm{n}=24)$ without metabolic syndrome, while $\mathrm{n}=$ 4 subjects developed it after twelve weeks. The difference between upgrading and worsening was highly significant $(\mathrm{p}<0.001)$.

The CV risk SCORE was significantly higher in subjects with the metabolic syndrome than in subjects without the metabolic syndrome both at baseline and at the end of the study (Table 6).

Additionally, we compared the incidence of the metabolic syndrome with the individuals identified as high risk. The percentage of subjects at high risk (SCORE $\geq$ $5 \%)$ decreased from $7.4 \%(\mathrm{n}=7)$ at baseline to $5.3 \%(\mathrm{n}$ $=5$ ) after the intervention. At baseline, six out of seven individuals with a SCORE $\geq 5 \%$ (high risk) also had a metabolic syndrome. After twelve weeks, three out of five high risk patients were also identified with a metabolic syndrome, whereas two individuals at high risk did not have a metabolic syndrome.

\section{Discussion}

Obesity in men and women is associated with a higher prevalence of the metabolic syndrome and CVD [21]. It

Table 6. Comparison of the risk SCORE in subjects with and without the metabolic syndrome in the SCORE subgroup aged $\geq 40$ years at baseline and after twelve weeks (n =95).

\begin{tabular}{cccc}
\hline & $\begin{array}{c}\text { With } \\
\text { metabolic } \\
\text { syndrome }\end{array}$ & $\begin{array}{c}\text { Without } \\
\text { metabolic } \\
\text { syndrome }\end{array}$ & $\mathrm{p}^{\mathrm{a}}$ \\
\hline baseline & & & \\
$\mathrm{N}$ & 64 & 31 & \\
$\begin{array}{c}\text { SCORE [\%] } \\
\text { Subjects at high risk } \\
\text { [n] }\end{array}$ & $2.18 \pm 2.05$ & $0.97 \pm 1.11$ & $\mathbf{< 0 . 0 0 1}$ \\
$\begin{array}{c}12 \text { weeks } \\
\mathrm{N}\end{array}$ & 6 & 1 & \\
$\begin{array}{c}\text { SCORE [\%] } \\
\text { Subjects at high risk } \\
{[\mathrm{n}]}\end{array}$ & $1.92 \pm 1.85$ & $1.04 \pm 1.2$ & $\mathbf{0 . 0 0 2}$ \\
\hline
\end{tabular}

${ }^{\mathrm{a} M a n n-W h i t n e y ~ U}$ test. 
is estimated that, depending on the corresponding definition, ethnicity and country, $20 \%-35 \%$ of the adult population are affected by a metabolic syndrome [4,22,23]. Results from a cross-sectional study on the prevalence and regional distribution of the metabolic syndrome in primary care practices in Germany showed an age-standardized prevalence of the metabolic syndrome of $19.8 \%$ ( $22.7 \%$ in men and $18.0 \%$ in women) $[24,25]$. The criteria of the metabolic syndrome were exactly the same criteria that were used in our study. The prevalence of the metabolic syndrome in this study population at baseline was $63 \%$. While, in accordance with Moebus et al. 2008, men were significantly more often concerned than women, the overall prevalence in our study was almost three times higher. A former interventional trial with 185 obese individuals showed a comparable initial prevalence of $68 \%$ [15].

According to numerous experts, weight loss is of primary importance for the management of the metabolic syndrome $[4,19,26]$. Studies have shown that a moderate weight loss and lifestyle modifications are effective for improving several components of the metabolic syndrome $[15,16,27,28]$. Results of our study demonstrated that a 12-week weight reduction programme reduces single aspects of the metabolic syndrome and the overall prevalence of the metabolic syndrome as well. In this context, weight loss was statistically significant related to the changes in components of the metabolic syndrome (Table 4). The majority of the metabolic syndrome variables improved in response to this intervention (Table 2). The highest improvements after weight loss were seen in the variables WC and blood pressure. These two factors have also been shown to be most frequent in men and women with metabolic syndrome [29].

The clustering of risk factors and the obvious improvement with weight reduction and correlation to weight change support the hypothesis that obesity plays a central role in the pathogenesis of this syndrome [15].

In contrast to the high prevalence of the metabolic syndrome in this study, the average 10 -year CV risk of all study participants investigated was $1.88 \% \pm 0.19 \%$ and could be considered as quite low. As expected, the SCORE value was significantly higher in men than in women. Although the baseline 10-year CV risk was low, there was a highly significant improvement during intervention in men, women and in the total study group. The decrease in this $\mathrm{CV}$ risk SCORE could be connected with the weight loss and changes in BMI (Table 4). The percentage of individuals at high risk (SCORE $\geq 5 \%$ ) was low (7.4\%) as well, and did not change remarkably. Currently, comparative data related to risk SCORE assessment from a German population group is rare. The CV risk SCORE was assessed in a nationwide cross-sectional point prevalence study with a sample of unselected patients $(\mathrm{n}=10,323$ men, $\mathrm{n}=18,852$ women, aged $35-65$ years). The prevalence of patients that had a low SCORE risk $(10$-year risk $<5 \%)$ in relation to the waist circumference was $76 \%-89 \%$ in men and $97 \%-99 \%$ in women [30]. In this study, a low SCORE risk (10-year risk $<5 \%$ ) was evaluated in $92.6 \%$ of the subjects at baseline and in $94.7 \%$ after twelve weeks of intervention.

However, in a cohort of 7641 primary care outpatients aged $\geq 50$ years with no CV disease, $57.1 \%$ of German patients (38.4\% of European patients) overall were considered to be at high CV risk based on a SCORE total of $\geq 5 \%$ [14]. In this connection, it was claimed that there might be an overestimation of $\mathrm{CV}$ risk predicted by the SCORE risk function in European populations [14,31, 32].

It must be pointed out that there might be limitations for the use of the German risk charts for this collective presented and in this investigation. Looking at the subjects' characteristics at the beginning of the study, including the grade of obesity and the significantly elevated parameters, such as WC, SBP, DBP, TC, and TG, it seems obvious that the SCORE values underestimated the 10-year CV risk of the subjects assessed. It should be noted that the overall risk in obese people in the guidance of the SCORE tables may be higher than indicated in the calculations. It is merely a note that is not backed by an actual value. We have to assume, however, that the actual extent of the CV risk in this collective is considerably higher.

In light of the risk SCORE model, the database of the European Heartscore project has to be considered. The SCORE database only includes fatal endpoints (e.g. cardiac death). This means a smaller sample size and, consequently, lower 10-year risks. The limitation of the SCORE project on CV mortality is based on the fact that standardized data for this endpoint are updated constantly and are available at each regional level. This does not apply to data on morbidity.

Although the CV risk SCORE might be underestimated in the current calculations, it is frequently used in clinical practice. In a multinational, cross-sectional study in twelve European countries (EURIKA), 58.3\% of all German and $52.0 \%$ of all European physicians used the global risk SCORE most commonly [14].

The metabolic syndrome is characterized by the common occurrence of abdominal obesity, hypertension, dyslipidemia, and hyperglycaemia as an expression of insulin resistance [33]. The presence of the metabolic syndrome confers an increased risk for type 2 diabetes mellitus and CVDs [9,34]. It was, therefore, possible to demonstrate in the present study that the CV risk SCORE calculated was increased in patients with metabolic syn- 
drome (Table 6). An increased CV risk was observed in patients with the metabolic syndrome in other studies as well [35].

In contrast to the results of the SCORE calculation, the diagnosis of the metabolic syndrome gave clearer information about the extent of a cardiometabolic risk within the collective investigated. This difference possibly results from the fact that the criteria of the metabolic syndrome (WC, DBP and fasting glucose) are not considered in the risk SCORE. The combination of risk factors of metabolic syndrome, therefore, leads to a different assessment of CV risk [36].

According to the NCEP ATP-III (2002), risk scores such as SCORE or Framingham risk score were developed for assessing CV risk in the short-term ( $\leq 10$ years), whereas identification of individuals with the metabolic syndrome is needed for long-term CV and metabolic risk assessment [19,36].

\section{Conclusion}

The metabolic syndrome was present in over two-thirds of overweight and obese subjects enrolling in this weight reduction intervention. A moderate weight loss over twelve weeks led to an improvement of all components of the metabolic syndrome. Weight loss, therefore, was associated with the changes in each of the factors of the metabolic syndrome. Whereas the occurrence of the metabolic syndrome in this study was high, the average CV risk SCORE was comparatively low. However, there was again a significant improvement during intervention in the study population. The CV risk SCORE might be underestimated in the current calculations. In sum, the diagnosis of a metabolic syndrome was more meaningful than risk SCORE calculations.

\section{REFERENCES}

[1] C. R. Balistreri, C. Caruso and G. Candore, "The Role of Adipose Tissue and Adipokines in Obesity-Related Inflammatory Diseases," Mediators of Inflammation, 2010, Article ID 802078. http://dx.doi.org/10.1155/2010/802078

[2] S. L. Doyle, C. L. Donohoe, J. Lysaght and J. V. Reynolds, "Visceral Obesity, Metabolic Syndrome, Insulin Resistance and Cancer," Proceedings of the Nutrition Society, Vol. 71, No. 1, 2012, pp. 181-189. http://dx.doi.org/10.1017/S002966511100320X

[3] C. L. Donohoe, S. L. Doyle and J. V. Reynolds, "Visceral Adiposity, Insulin Resistance and Cancer Risk," Diabetology \& Metabolic Syndrome, Vol. 3, 2011, p. 12. http://dx.doi.org/10.1186/1758-5996-3-12

[4] M. A. Cornier, D. Dabelea, T. L. Hernandez, R. C. Lindstrom, A. J. Steig, N. R. Stob, R. E. Van Pelt, H. Wang and R. H. Eckel, "The Metabolic Syndrome," Endocrine
Reviews, Vol. 29, No. 7, 2008, pp. 777-822.

http://dx.doi.org/10.1210/er.2008-0024

[5] P. Maison, C. D. Byrne, C. N. Hales, N. E. Day and N. J. Wareham, "Do Different Dimensions of the Metabolic Syndrome Change Together Over Time? Evidence Supporting Obesity as the Central Feature," Diabetes Care, Vol. 24, No. 10, 2001, pp. 1758-1763. http://dx.doi.org/10.2337/diacare.24.10.1758

[6] A. Koster, S. Stenholm, D. E. Alley, L. J. Kim, E. M. Simonsick, A. M. Kanaya, M. Visser, D. K. Houston, B. J. Nicklas, F. A. Tylavsky, S. Satterfield, B. H. Goodpaster, L. Ferrucci and T. B. Harris, "Health ABC Study. Body Fat Distribution and Inflammation among Obese Older Adults with and without Metabolic Syndrome," Obesity (Silver Spring), Vol. 18, No. 12, 2010, pp. 2354-2361. http://dx.doi.org/10.1038/oby.2010.86

[7] A. J. Cameron, D. W. Dunstan, N. Owen, P. Z. Zimmet, E. L. Barr, A. M. Tonkin, D. J. Magliano, S. G. Murray, T. A. Welborn and J. E. Shaw, "Health and Mortality Consequences of Abdominal Obesity: Evidence from the AusDiab Study," Medical Journal of Australia, Vol. 191, No. 4, 2009, pp. 202-208.

[8] S.A Ritchie and J. M. Connell, "The Link between Abdominal Obesity, Metabolic Syndrome and Cardiovascular Disease," Nutrition, Metabolism \& Cardiovascular Diseases, Vol. 17, No. 4, 2007, pp. 319-326. http://dx.doi.org/10.1016/j.numecd.2006.07.005

[9] B. Isomaa, P. Almgren, T. Tuomi, B. Forsen, K. Lahti, M. Nissen, M. R. Taskinen and L. Groop, "Cardiovascular Morbidity and Mortality Associated with the Metabolic Syndrome," Diabetes Care, Vol. 24, No. 4, 2001, pp. 683-689. http://dx.doi.org/10.2337/diacare.24.4.683

[10] P. W. Wilson, R. B. D’Agostino, D. Levy, A. M. Belanger, H. Silbershatz and W. B. Kannel, "Prediction of Coronary Heart Disease Using Risk Factor Categories," Circulation, Vol. 97, No. 18, 1998, pp. 1837-1847. http://dx.doi.org/10.1161/01.CIR.97.18.1837

[11] G. Assmann, P. Cullen and H. Schulte, "Simple Scoring Scheme for Calculating the Risk of Acute Coronary Events Based on the 10-Year Follow-Up of the Prospective Cardiovascular Munster (PROCAM) Study," Circulation, Vol. 105, No. 3, 2002, pp. 310-315. http://dx.doi.org/10.1161/hc0302.102575

[12] R. M. Conroy, K. Pyorala, A. P. Fitzgerald, S. Sans, A. Menotti, B. G. De, P. Ducimetiere, P. Jousilahti, U. Keil, I. Njolstad, R. G. Oganov, T. Thomsen, H. Tunstall-Pedoe, A. Tverdal, H. Wedel, P. Whincup, L. Wilhelmsen and I. M. Graham, "Estimation of Ten-Year Risk of Fatal Cardiovascular Disease in Europe: The SCORE Project," European Heart Journal, Vol. 24, No. 11, 2003, pp. 9871003. http://dx.doi.org/10.1016/S0195-668X(03)00114-3

[13] U. Keil, A. Fitzgerald, H. Gohlke, J. Wellmann and H. Hense, "Risk Stratification of Cardiovascular Diseases in Primary Prevention-The New SCORE-Deutschland Risk Charts," Deutsches Ärzteblatt, Vol. 102, No. 25, 2005, pp. A1808-A1812.

[14] R. E. Schmieder, M. Goebel and P. Bramlage, "Barriers to Cardiovascular Risk Prevention and Management in 
Germany-An Analysis of the EURIKA Study," Journal of Vascular Health and Risk Management, Vol. 8, 2012, pp. 177-186.

[15] C. C. Case, P. H. Jones, K. Nelson, S. E. O'Brian and C. M. Ballantyne, "Impact of Weight Loss on the Metabolic Syndrome," Diabetes, Obesity and Metabolism, Vol. 4, No. 6, 2002, pp. 407-414. http://dx.doi.org/10.1046/j.1463-1326.2002.00236.x

[16] P. Ilanne-Parikka, J. G. Eriksson, J. Lindstrom, M. Peltonen, S. Aunola, H. Hamalainen, S. Keinanen-Kiukaanniemi, M. Laakso, T. T. Valle, J. Lahtela, M. Uusitupa and J. Tuomilehto, "Effect of Lifestyle Intervention on the Occurrence of Metabolic Syndrome and Its Components in the Finnish Diabetes Prevention Study," Diabetes Care, Vol. 31, No. 4, 2008, pp. 805-807. http://dx.doi.org/10.2337/dc07-1117

[17] A. Ferland and R. H. Eckel, "Does Sustained Weight Loss Reverse the Metabolic Syndrome?" Current Hypertension Reports, Vol. 13, No. 6, 2011, pp. 456-464. http://dx.doi.org/10.1007/s11906-011-0221-z

[18] J. Willers, S. Plötz and A. Hahn, "The Combination of a High-Protein Formula Diet and Polyglucosamine Decreases Body Weight and Parameters of Glucose and Lipid Metabolism in Overweight and Obese Men and Women," European Journal of Food Research \& Review, Vol. 2, No. 1, 2012, pp. 29-45.

[19] NCEP ATP-III, "Third Report of the National Cholesterol Education Program (NCEP) Expert Panel on Detection, Evaluation, and Treatment of High Blood Cholesterol in Adults (Adult Treatment Panel III) Final Report," Circulation, Vol. 106, No. 25, 2002, pp. 3143-3421.

[20] K. G. Alberti, R. H. Eckel, S. M. Grundy, P. Z. Zimmet, J. I. Cleeman, K. A. Donato, J. C. Fruchart, W. P. James, C. M. Loria and S. C. Smith, "Harmonizing the Metabolic Syndrome: A Joint Interim Statement of the International Diabetes Federation Task Force on Epidemiology and Prevention; National Heart, Lung, and Blood Institute; American Heart Association; World Heart Federation; International Atherosclerosis Society; and International Association for the Study of Obesity," Circulation, Vol. 120, No. 16, 2009, pp. 1640-1645. http://dx.doi.org/10.1161/CIRCULATIONAHA.109.1926 $\underline{44}$

[21] R. Weiss, J. Dziura, T. S. Burgert, W. V. Tamborlane, S. E. Taksali, C. W. Yeckel, K. Allen, M. Lopes, M. Savoye, J. Morrison, R. S. Sherwin and S. Caprio, "Obesity and the Metabolic Syndrome in Children and Adolescents," The New England Journal of Medicine, Vol. 350, No. 23, 2004, pp. 2362-2374. http://dx.doi.org/10.1056/NEJMoa031049

[22] H. Neuhauser and U. Ellert, "Estimation of the Metabolic Syndrome Prevalence in the General Population in Germany," Journal of Public Health, Vol. 16, No. 3, 2008, pp. 221-227. http://dx.doi.org/10.1007/s10389-007-0168-3

[23] E. S. Ford, W. H. Giles and W. H. Dietz, "Prevalence of the Metabolic Syndrome among US Adults: Findings from the Third National Health and Nutrition Examination Survey," JAMA, Vol. 287, No. 3, 2002, pp. 356-359.

\section{http://dx.doi.org/10.1001/jama.287.3.356}

[24] S. Moebus, J. Hanisch, P. Bramlage, C. Losch, H. Hauner, J. Wasem and K. H. Jockel, "Regional Differences in the Prevalence of the Metabolic Syndrome in Primary Care Practices in Germany," Deutsches Ärzteblatt International, Vol. 105, No. 12, 2008, pp. 207-213.

[25] S. Moebus, J. U. Hanisch, M. Neuhauser, P. Aidelsburger, J. Wasem and K. H. Jockel, "Assessing the Prevalence of the Metabolic Syndrome According to NCEP ATP III in Germany: Feasibility and Quality Aspects of a Two Step Approach in 1550 Randomly Selected Primary Health Care Practices," German Medical Science, Vol. 4, 2006, Doc07.

[26] S. S. Daskalopoulou, D. P. Mikhailidis and M. Elisaf, "Prevention and Treatment of the Metabolic Syndrome," Angiology, Vol. 55, No. 6, 2004, pp. 589-612.

[27] D. König, P. Deibert, I. Frey, U. Landmann and A. Berg, "Effect of Meal Replacement on Metabolic Risk Factors in Overweight and Obese Subjects," Annals of Nutrition and Metabolism, Vol. 52, No. 1, 2008, pp. 74-78. http://dx.doi.org/10.1159/000119416

[28] L. J. Joseph, R. L. Prigeon, J. B. Blumenthal, A. S. Ryan and A. P. Goldberg, "Weight Loss and Low-Intensity Exercise for the Treatment of Metabolic Syndrome in Obese Postmenopausal Women," Journals of Gerontology Series A: Biological Sciences and Medical Sciences, Vol. 66, No. 9, 2011, pp. 1022-1029. http://dx.doi.org/10.1093/gerona/glr093

[29] S. Moebus, J. U. Hanisch, C. Lösch, P. Bramlage, H. Schunkert, H. Hauner, J. Wasem and K. H. Jöckel, “Arterial Hypertension and Abdominal Obesity Are the Most Important Factors of the Metabolic Syndrome in a Cohort of 35,869 Patients in Primary Care," Journal of Hypertension, Vol. 12, No. 2, 2008, pp. 7-11.

[30] H. Schunkert, S. Moebus, J. Hanisch, P. Bramlage, E. Steinhagen-Thiessen, H. Hauner, J. Weil, J. Wasem and K. H. Jockel, "The Correlation between Waist Circumference and ESC Cardiovascular Risk Score: Data from the German Metabolic and Cardiovascular Risk Project (GEMCAS)," Clinical Research in Cardiology, Vol. 97, No. 11, 2008, pp. 827-835. http://dx.doi.org/10.1007/s00392-008-0694-1

[31] H. Ulmer, B. Kollerits, C. Kelleher, G. Diem and H. Concin, "Predictive Accuracy of the SCORE Risk Function for Cardiovascular Disease in Clinical Practice: A Prospective Evaluation of 44,649 Austrian Men and Women," European Journal of Cardiovascular Prevention \& Rehabilitation, Vol. 12, No. 5, 2005, pp. 433-441. http://dx.doi.org/10.1097/01.hjr.0000174791.47059.80

[32] A. S. Lindman, M. B. Veierod, J. I. Pedersen, A. Tverdal, I. Njolstad and R. Selmer, "The Ability of the SCORE High-Risk Model to Predict 10-Year Cardiovascular Disease Mortality in Norway," European Journal of Cardiovascular Prevention \& Rehabilitation, Vol. 14, No. 4, 2007, pp. 501-507. http://dx.doi.org/10.1097/HJR.0b013e328011490a

[33] J. Levesque and B. Lamarche, "The Metabolic Syndrome: Definitions, Prevalence and Management," Journal of 
Nutrigenetics and Nutrigenomics, Vol. 1, No. 3, 2008, pp. 100-108. http://dx.doi.org/10.1159/000112457

[34] P. W. Wilson, R. B. D’Agostino, H. Parise, L. Sullivan and J. B. Meigs, "Metabolic Syndrome as a Precursor of Cardiovascular Disease and Type 2 Diabetes Mellitus," Circulation, Vol. 112, No. 20, 2005, pp. 3066-3072. http://dx.doi.org/10.1161/CIRCULATIONAHA.105.5395 $\underline{28}$

[35] S. Tonstad and I. Hjermann, "A High Risk Score for Coronary Heart Disease Is Associated with the Metabolic
Syndrome in 40-Year-Old Men and Women," Journal of Cardiovascular Risk, Vol. 10, No. 2, 2003, pp. 129-135. http://dx.doi.org/10.1097/00043798-200304000-00008

[36] J. Postler, A. Bosy-Westphal, B. Hitze, M. Pfeuffer and M. J. Müller, "Vergleich Dreier Kardiovaskulärer RisikoScores (Framingham-Score, PROCAM-Score, SCOREDeutschland) und des Metabolischen Syndroms bei Erwachsenen der Kieler Adipositas-Präventionsstudie (KOPS)," Aktuellen Ernährungsmedizin, Vol. 32, 2007, pp. 307-314. http://dx.doi.org/10.1055/s-2007-986242 